J. Biosoc. Sci., (2013) 45, 517-545, (C) Cambridge University Press, 2012. The online version of this article is published within an Open Access environment subject to the conditions of the Creative Commons Attribution-NonCommercial-ShareAlike licence <http://creativecommons.org/licenses/ by-nc-sa/3.0/>. The written permission of Cambridge University Press must be obtained for commercial re-use.

doi:10.1017/S0021932012000466 First published online 27 Sept 2012

\title{
WILL MASS DRUG ADMINISTRATION ELIMINATE LYMPHATIC FILARIASIS? EVIDENCE FROM NORTHERN COASTAL TANZANIA
}

\author{
MELISSA PARKER* AND TIM ALLEN $\dagger$ \\ *Centre for Research in International Medical Anthropology, Brunel University, UK and \\ $\dagger$ Department of International Development, London School of Economics, UK
}

\begin{abstract}
Summary. This article documents understandings and responses to mass drug administration (MDA) for the treatment and prevention of lymphatic filariasis among adults and children in northern coastal Tanzania from 2004 to 2011. Assessment of village-level distribution registers, combined with self-reported drug uptake surveys of adults, participant observation and interviews, revealed that at study sites in Pangani and Muheza districts the uptake of drugs was persistently low. The majority of people living at these highly endemic locations either did not receive or actively rejected free treatment. A combination of social, economic and political reasons explain the low uptake of drugs. These include a fear of treatment (attributable, in part, to a lack of trust in international aid and a questioning of the motives behind the distribution); divergence between biomedical and local understandings of lymphatic filariasis; and limited and ineffective communication about the rationale for mass treatment. Other contributory factors are the reliance upon volunteers for distribution within villages and, in some locations, strained relationships between different groups of people within villages as well as between local leaders and government officials. The article also highlights a disjuncture between self-reported uptake of drugs by adults at a village level and the higher uptake of drugs recorded in official reports. The latter informs claims that elimination will be a possibility by 2020 . This gives voice to a broader problem: there is considerable pressure for those implementing MDA to report positive results. The very real challenges of making MDA work are pushed to one side - adding to a rhetoric of success at the expense of engaging with local realities. It is vital to address the kind of issues raised in this article if current attempts to eliminate lymphatic filariasis in mainland coastal Tanzania are to achieve their goal.
\end{abstract}

\section{Introduction}

Current endeavours to eliminate lymphatic filariasis have been hailed as 'a best buy in global health' (Ottesen, 2008, e317) and 'the most effective pro-poor public health programme' (Molyneux, 2003, p. 1). They are part of an international agenda to 'rescue 
the bottom billion through the control of neglected tropical diseases' (Hotez et al., 2009, p. 1570) with a view to helping 'make poverty history' (Molyneux et al., 2005, p. 106). While there may be a degree of fundraising rhetoric in such statements, there is no doubt that lymphatic filariasis presents a major public health problem for large numbers of impoverished people. Recent estimates suggest that around 120 million people living in tropical and sub-tropical environments are affected, with approximately 40 million displaying clinical signs of infection such as hydrocele (swollen scrotum), lymphoedema/elephantiasis and a further 80 million people experiencing sub-clinical signs of infection (Taylor et al., 2010).

Strategies to eliminate lymphatic filariasis currently rely heavily on the mass distribution of drugs, free of charge, to all adults and children aged five or more living in endemic areas. The drugs being distributed are albendazole, in combination with either diethylcarbamazine citrate (DEC) or ivermectin; and recent reports suggest that more than 570 million individuals, residing in 51 countries where lymphatic filariasis is endemic, have received these drugs (Taylor et al., 2010). There are several reasons for promoting mass drug administration (MDA).

First, it is important to break the cycle of transmission between mosquitoes and human beings. Anopheles, Culex, Aedes and Mansonia mosquitoes are all capable of transmitting parasitic worms (Wuchereria Bancrofti in Africa) that cause the disease, lymphatic filariasis, in humans. The mass distribution of drugs provides an opportunity to interrupt transmission, because the tablets have the effect of reducing the circulation of microfilariae (the larvae of the parasitic worms circulating in the blood of infected individuals). This, in turn, helps to prevent onward transmission.

Second, elimination of the disease is thought to be achievable with the drugs mentioned above if a large enough proportion of the population swallow the tablets being distributed. The necessary rates of drug take-up have been variously estimated at $65-80 \%$ over four to six years (Mohammed et al., 2006) and 70-90\% over six or more years (Michael et al., 2004). In areas where the prevalence of microfilariae is greater than $10 \%$, Michael et al. (2004) have suggested that coverage levels of $90 \%$ or more may be necessary. Whatever the requisite coverage levels, multiple rounds of treatment are essential because the drugs currently being used do not kill the adult worms. Instead, they reduce the circulation of microfilariae until the worms naturally die off, and it can take six years for this to occur (Michael et al., 2004; Bockarie \& Deb, 2010).

Additional reasons for promoting MDA include the fact that two pharmaceutical companies, GlakoSmithKline and Merck, have agreed to donate the relevant drugs until lymphatic filariasis has been eliminated from the globe (WHO, 2012). The drugs, it is argued, can usually be distributed through existing national health mechanisms to volunteers in the targeted communities. They are also considered to be safe enough to be used without testing for infection, making it ethical, as well as cheap, to treat everyone. In sum, it is argued that MDA for lymphatic filariasis is an 'easy-to-do' and inexpensive health intervention (Molyneux, 2003, p. 13), a view that underpins the World Health Organization's Global Programme to Eliminate Lymphatic Filariasis. By 2008, the results were reported to be 'staggering' and elimination of the disease was anticipated to be a real possibility by 2020 ('End in sight' for elephantiasis, BBC, 8th October 2008, http://news.bbc.co.uk/1/hi/health/7659222.stm). Continuing optimism 
is reflected in statements such as those by the WHO Department of Control of Neglected Tropical Diseases in 2011, suggesting the campaign is 'halfway towards eliminating lymphatic filariasis' (http://www.who.int/neglected_diseases/integrated_media/integrated_ media_urogenital_lf_2011/en/index.html), and by those associated with the January 2012 joint London Declaration on Neglected Tropical Diseases (NTDs), in which partners pledged new levels of collaboration and announced a co-ordinated push to accelerate progress toward the eradication of lymphatic filariasis and the control or elimination of a range of other NTDs (http://www.dfid.gov.uk/Documents/publications1/NTD \% 20Event $\% 20-\% 20$ Table $\% 20$ of $\% 20$ Commitments.pdf).

The Tanzanian National Lymphatic Filariasis Elimination Programme (TNLFEP) is part of these global operations to eliminate the disease. The TNLFEP began in 2000 and has expanded, year on year. In 2009, it was reported that it had covered 34 districts in six regions, with 9.2 million people having been treated over a period of eight years (Malecela et al., 2009a). Efforts to eliminate lymphatic filariasis from Tanzania are also part of the national programme to control neglected tropical diseases (United Republic of Tanzania, 2009). This programme was established in 2009 with a view to co-ordinating efforts to control or eradicate a variety of tropical diseases including schistosomiasis, soil-transmitted helminths, onchocerciasis, trachoma and lymphatic filariasis. It is recognized in reports and official statements that an integrated and holistic approach to lymphatic filariasis (and other neglected tropical diseases) is the ideal, and that MDA should be combined with other methods. However, it would be fair to say that, in practice, the focus has primarily been on the distribution of donated drugs. Thus, the TNLFEP is meant to have other components. In addition to the mass distribution of ivermectin and albendazole, it is intended that there should be vector control (involving the use of bed nets and the reduction of breeding sites for mosquitoes); lymphoedema management; and hydrocelectomies (involving surgery for scrotal swelling caused by the parasitic worm, Wuchereria bancrofti). Although the emphasis given to these latter components may be different in other locations, such as Zanzibar (Mohammed et al., 2006) and Mafia (Malecela et al., 2009a), at locations studied in this paper, vector control was receiving almost no attention, and lymphoedema management was very limited.

\section{Previous research on lymphatic filariasis in mainland coastal Tanzania}

A variety of epidemiological and health policy research has been undertaken on lymphatic filariasis in coastal Tanzania (see, for example, Kolstrup et al., 1981; Meyrowitsch et al., 1995, 2004; Nielsen et al., 2006; Rwegoshora et al., 2007; Simonsen et al., 2005, 2010; Malecela et al., 2009b). Much of this research documents the prevalence of microfilariae as well as visible signs of infection such as swollen scrotums, legs and feet. Simonsen et al. (2010), for example, reported that in Kirare, a sentinel surveillance site located about $20 \mathrm{~km}$ from the regional capital of Tanga, the overall prevalence of microfilariae among individuals over the age of one was $24.5 \%$, and it was $53.3 \%$ for Wuchereria bancrofti-specific circulating antigen. They also noted that $4.1 \%$ adults aged 20 years or more had elephantiasis of the leg and $32.8 \%$ adult men had hydrocele. These data were collected in September 2004, immediately before the TNLFEP began the first round of treatment. They indicate that, if the estimates of Michael et al. (2004) are 
correct, a daunting annual MDA take-up rate of at least $90 \%$ would be required to interrupt disease transmission.

Simonsen et al. go on to document the effect of three rounds of mass treatment with ivermectin and albendazole to adults and children aged five or more living in Kirare. The reported findings suggest the uptake of drugs was less than the target rate, and that uptake declined over time. Self-reported uptake fell from 82\% in October 2004 to $79 \%$ in February 2006 and 69.9\% in May 2007. Beneficial biological effects for the population were nevertheless observed. Human infection with microfilariae declined, and this led to a reduction in transmission. However, the effects thereafter levelled off and transmission still occurred after the third round of MDA, albeit at a lower level. Concerns were raised about the length of time between rounds of treatment (as they were longer than the recommended period of one year) as well as the fact that mass treatment had limited influence on adult worm burden. The article concludes by highlighting the 'waning effect' of MDA and the need for careful monitoring and evaluation. This includes the need to make more accurate assessments of the number of people receiving and actually swallowing tablets. With respect to the latter point, the authors query the high rates of drug uptake recorded in official reports. This, in turn, raises the additional issue of whether or not the uptake of drugs in Kirare represents the norm, or whether proximity to Tanga town (the location of the regional referral hospital and medical headquarters) combined with the regular visits of Tanga-based researchers, facilitated higher than average treatment coverage for the region. It is likely that this is the case as it would have been extremely difficult to have collected blood samples without a significant proportion of participants understanding the purpose of the research and the rationale for mass treatment.

Anthropologists are well-placed to assist with endeavours to assess the social and biological consequences of mass treatment for the control of neglected tropical diseases (NTDs) such as lymphatic filariasis. To the authors' knowledge, they have not, as yet, explored local responses to mass treatment programmes seeking to eliminate lymphatic filariasis. This article attempts to reverse this trend. Building on research undertaken in north-western, northern and south-eastern Uganda on two other neglected tropical diseases, schistosomiasis and soil-transmitted helminths (Parker et al., 2008, 2012; Parker \& Allen, 2011), it addresses the following questions: is current enthusiasm for the elimination of lymphatic filariasis on the global stage shared by those on the receiving end of these programmes? Is it appropriate to assume that adults will be willing, if not grateful, to swallow tablets if they are provided free of charge, in the interests of maintaining or preserving their own health? How does the social context in which mass distribution occurs influence the uptake of drugs?

\section{Field sites and methods}

The article is based on research undertaken in northern coastal Tanzania from July to September 2007 and July to August 2011. In 2007, ten weeks of fieldwork were undertaken in the adjoining villages of Mwembeni and Jaira in Pangani district, the small town of Kigombe in Muheza district and several other villages close to the town in this district. Follow-up research occurred four years later over a period of five weeks. Field research was led by the two authors. They were assisted by a group of four 
locally recruited researchers in 2007 and five locally recruited researchers in 2011, all of whom were either secondary-school leavers or graduates who had been unable to find employment.

Research in Mwembeni and Jaira villages in 2007 involved participant observation in a wide range of settings, including visits to homesteads, attending local healing ceremonies, talking to villagers cultivating maize and cassava, and visiting local dispensaries and the district hospital. In addition, 30 open-ended, unstructured interviews were undertaken with local healers, health care providers and village elders; and village meetings were held at various points during fieldwork to discuss the rationale for the research and to feed back provisional findings. To complement this work, a $20 \%$ random sample of households was generated from the 2004 Ministry of Health registers documenting the uptake of drugs for lymphatic filariasis. Semi-structured interviews were then undertaken with one adult from each selected household. Seventy-three semi-structured interviews were undertaken with adults in Mwembeni village and 35 semi-structured interviews were undertaken with adults in Jaira village.

In July-August 2011, a further 118 semi-structured interviews were undertaken with randomly selected adults in Mwembeni. In contrast to 2007, it was not possible to use the Ministry of Health registers as a way of systematically identifying households in Mwembeni as the records were no longer based on census data detailing the names of all residents living in the villages. Instead, the registers were simply a list of names of people who had received treatment. A sample of households was thus derived by visiting every other household in each of the sub-divisions of the village. In addition, participant observation and fifteen open-ended, unstructured interviews were undertaken as well as an open meeting in the village to discuss key issues emerging from the research.

In Muheza district, research was undertaken in Kigombe town and its environs. For administrative purposes the area is divided into Kigombe East (and its subvillages) and Kigombe West (and its sub-villages). The peri-urban area of Kigombe East runs along the edge of the sea. In addition, there are numerous villages, spread out over many kilometres, located to the north-east along the coast road running towards Tanga town. The peri-urban area of Kigombe West spreads inland from the coast road and includes more distant rural villages such as Mchangani and Ndonde. With the exception of the peri-urban area of Kigombe West (for which there was a household list produced by an American anthropologist, Suzi Krehbiel, who had lived in the area in 2006), local registers were unavailable or incomplete. It was thus necessary to derive a sample of households by visiting every second home with a view to interviewing a similar proportion of people to that achieved in Mwembeni and Jaira. A total of 146 semi-structured interviews were undertaken in Kigombe West (including the sub-villages of Mchangani and Ndonde) and Kigombe East (including the subvillages of Sinawe, Gawani and the village of Kitongoji) in 2007 and 144 semistructured interviews in 2011. The methods employed were the same as those described for Mwembeni and Jaira in Pangani district, including a similar number of unstructured interviews.

Research was also undertaken in 2007 in two villages located close to the district capital, Muheza town: Magila and Bwembwera. Here, 30 households were randomly selected in Magila and 51 households were randomly selected in Bwembwera. Accord- 
ing to the lists of households kept by the village chairmen, this represented more than $20 \%$ of the estimated number of households. Semi-structured interviews were then undertaken with one adult from each selected household.

All semi-structured interviews undertaken in Pangani and Muheza districts elicited information about whether or not the adult being interviewed accepted free drugs for the treatment and prevention of lymphatic filariasis. Information and ideas emerging from participant observation fieldwork and open-ended, unstructured interviews were subsequently used to interpret these quantitative data. Swahili is the dominant local language in this part of Tanzania, as well as being the national language. Migrants into the region all spoke Swahili, even when they also spoke their own languages (such as Makonde). The vast majority of semi-structured and unstructured interviews, as well as village meetings, were thus undertaken in Swahili.

Finally, an endeavour was made to elicit the perspectives of village-based drug distributors and district officials involved in the mass drug administration programme for the control of lymphatic filariasis. Official records monitoring the uptake of drugs by staff from the Ministry of Health were looked at wherever possible, and these were discussed with the relevant staff in English.

\section{Mwembeni and Jaira villages, Pangani district}

Mwembeni village is about $8 \mathrm{~km}$ from Pangani town and lies on the main road that links Muheza town to the coast. It is one of three villages that form part of Madanga ward, and one of eight villages that form part of Madanga division. According to census data published in 2006, 1126 people live in Mwembeni. The village is divided into four sub-divisions: Mzia, Mwembeni, Makuyuni and Nunda. It is socially diverse, with Christians (Protestant and Catholic) and Muslims (Sunni and Shia) living side-byside. The Christians are predominantly Makonde, and the Muslims are predominantly Zigua and Zaramo. There is inter-marriage between these groups, although tensions exist between Muslim groups (focused in particular on rival imams) as well as between Muslim and Christian groups. It is not unusual for Muslims to talk about the Makonde as migrants or 'refugees' from Mozambique, in spite of the fact that they have lived in the village for two and even three generations. Many of their homes are located at some distance from the village centres, in some cases in remote places. Mwembeni village has one primary school and one small madrasa (Islamic school). It also has several mosques and churches (both of the most basic variety). A small number of people have access to piped water from a tap every other day, and there are ten households with access to electricity, two of whom have a satellite dish. Broadly similar characteristics apply to Jaira village, which lies a few kilometres north of Mwembeni. According to Ministry of Health data collected in 2004, an estimated 539 people live in this village.

The majority of adults in Jaira and Mwembeni own or rent plots of land that they cultivate. Others are employed on a temporary basis as farm labourers. A diverse array of crops are grown including cassava, maize and rice. Coconut, orange, mango and banana trees are grown too, though most people do not have access to all these types of fruit trees. A small number of people fish for prawns in the river, and these are mainly sold in Pangani town. It is important to note that very few people have 
regular, salaried work. Historically, the large-scale production of sisal at nearby estates was an important source of regular employment, and explains the presence of so many Makonde. However, decline in the global demand for sisal has led to a decline in production and the laying off of staff. As part of the surveys on drug uptake discussed below, adults living in Mwembeni and Jaira were asked what they considered to be the most serious problems facing them: 58\% mentioned unemployment and 26\% mentioned inadequate health facilities.

\section{Kigombe and surrounding villages, Muheza district}

Kigombe is a small town that lies on the coastal road linking the town of Tanga to the town of Pangani. Although it is geographically much closer to Pangani, it is actually part of Muheza district. It takes around two hours to drive to the district capital. Access to the sea provides fishing opportunities to those with access to nets and boats, but the majority of people rely upon the cultivation of cassava, maize and rice to survive, just as they do in Mwembeni. Fifty-three per cent of surveyed adults highlighted unemployment as the most serious problem they faced compared with $31 \%$ who mentioned inadequate health facilities. There are several schools in Kigombe, including a madrasa, and there are also several mosques and a government dispensary. The population is mostly Muslim, but in common with Mwembeni, there is a Christian minority, generally living a little further inland at the edges of the sisal fields. Also like Mwembeni, there are divisions among the Muslims, but of a more intense nature. 'Radical' Islam has a presence (with some openly sympathetic to Al Qaida in 2007). There are also divisions between more orthodox Sunni Muslims and Muslims who are members of the Sudanese Ansar sect. In contrast to Mwembeni, Kigombe is characterized by the amplified call to prayer from rival mosques at night time. Other divisions relate to political activism, with the local chairman being a member of Civic United Front (CUF), a political party opposing the government.

\section{Local ideas about illness and misfortune}

Before addressing the specific issue of drug uptake for the treatment and prevention of lymphatic filariasis, it is helpful to note that the study populations were found to draw upon a broad range of ideas to understand illness and misfortune. Interpersonal and spiritual aspects of well-being are often used to interrogate biomedical understandings, with many kinds of illness being discussed in relation to the Swahili word uchawi. The term uchawi may be translated as 'witchcraft', but it does not necessarily have the same connotations as the English word. The majority of people interviewed in depth talked about uchawi as being a constant threat, and many were surprisingly open about the specific individuals who they suspected were most likely to use it. Even in the semistructured interviews, which were inevitably less probing, large numbers of people stated that uchawi presented a problem. Those thought to be responsible are mostly local healers or Christian migrants.

Notions about interpersonal and spiritual causes of affliction are also connected with beliefs about and experiences of spirit possession. Those local healers with high status were all found to be members of Swahili possession cults. In common with Giles 
(1987, 1999), it became apparent that, unlike most possession cults in other parts of Africa, these cults are closely connected with local hierarchies, and are expensive to join. Possession is viewed as something dangerous and frightening, but paradoxically, also carries high status and the possession cults operate as a parallel means of interpreting the spirit world to that of Islam. Indeed some of the practices observed were strikingly un-Islamic (such as the ritual drinking of sheep blood). To the authors' knowledge, no Christians were directly involved in these cults. It is also important to note that considerable emphasis was placed on the training of healers at public séances. For example, more than a dozen healers were present at a ritual that went on for several days at one of the villages of Kigombe and half a day was allocated to discussions between healers attending the ritual and those who had become new members of the cult and would in the future be acting themselves as healers. Emphasis was placed on the appropriate relationships they should have with their patients, implicitly contrasting them with the kinds of treatment expected at clinics. Their treatments involved a combination of local remedies, concocted from locally available substances, with spiritual and moral interpretations of affliction. The findings of respected healers carried weight, and were not necessarily complementary with biomedical interpretations and treatments, including those for lymphatic filariasis.

\section{Uptake of drugs for the treatment and prevention of lymphatic filariasis in Pangani and Muheza districts, Tanga region}

\section{Uptake of drugs at villages in Pangani and Muheza districts, 2004-2007}

By July 2007, three rounds of treatment had been distributed, free of charge, over a four-year period for lymphatic filariasis. These took place in 2004, 2006 and 2007. In both districts, registers were distributed by staff from the Ministry of Health to villagebased drug distributors prior to the first round of treatment in 2004. This enabled a detailed record to be made of the names and ages of people living in each household with a view to keeping a year-on-year record of the proportion of adults and children receiving drugs for the treatment and prevention of lymphatic filariasis.

In Mwembeni village, distributors were found to have kept meticulous records of the number of adults and children aged five and above who took the drugs for lymphatic filariasis. According to these registers, 59\% of adults and children eligible for treatment received the drugs in 2004; whereas $46 \%$ of them received treatment in 2006 and $34 \%$ received treatment in 2007 . In short, the registers suggested there had been a decline in the uptake of drugs. Data derived by selecting a $20 \%$ random sample of households and then interviewing one adult from each selected household also indicated a decline. That is, $71 \%$ of adults interviewed in Mwembeni said that they received treatment in 2004; whereas 49\% received treatment in 2006 and 35\% received treatment in 2007. These data are presented in Table 1.

The table also shows that very similar findings were recorded in neighbouring Jaira village. The Jaira registers suggested that 55\% received treatment in 2004; $43 \%$ received treatment in 2006 and $42 \%$ received treatment in 2007. In common with Mwembeni, a $20 \%$ random sample of households was taken from the 2004 Ministry of Health drug distribution registers. One adult was interviewed from each selected household, and 
Table 1. Uptake of drugs for the treatment and prevention of lymphatic filariasis among adults in Pangani district, Tanga region, 2004-2007

\begin{tabular}{lccc}
\hline & 2004 & 2006 & 2007 \\
\hline $\begin{array}{l}\text { Drug uptake among adults and children in village registers } \\
\quad \text { Mwembeni village }\end{array}$ & $202(59 \%)$ & $402(46 \%)$ & $306(34 \%)$ \\
$\quad$ Jaira village & $263(55 \%)$ & $164(43 \%)$ & $160(42 \%)$ \\
Self-reported drug uptake among interviewed adults & & & \\
$\quad$ Mwembeni village, $N=75$ & $53(71 \%)$ & $37(49 \%)$ & $26(35 \%)$ \\
Jaira village, $N=34$ & $19(56 \%)$ & $17(50 \%)$ & $13(38 \%)$ \\
\hline
\end{tabular}

${ }^{a}$ In Mwembeni village, the total number of people listed in the drug distributors' registers that were eligible for treatment was 345 in 2004, 869 in 2006 and 901 in 2007. The fact that fewer people appeared to be eligible for treatment in 2004 can almost certainly be attributed to the fact that some of the registers had been lost.

b In Jaira village, the total number of people listed in the drug distributors' registers that were eligible for treatment was 475 in 2004, 386 in 2006 and 386 in 2007. The fact that fewer people appeared to be eligible for treatment in 2006 and 2007, compared with 2004, is probably attributable to the fact that some of the registers had been lost.

data emerging from these interviews also conveyed a decline in the uptake of drugs. That is, 56\% adults received treatment in 2004, 50\% received treatment in 2006 and $38 \%$ received treatment in 2007.

Ministry of Health registers documenting the uptake of drugs in Kigombe and surrounding villages could not be located. However, data collected in the course of undertaking semi-structured interviews suggested a downward trend. Table 2 shows that $47 \%$ of those interviewed in Kigombe said they received treatment in $2004,45 \%$ received treatment in 2006 and $22 \%$ received treatment in 2007. A different picture emerged in the northern part of Muheza district. In the village of Bwembwera, interviews indicated that 47\% received treatment in 2004, 69\% received treatment in 2006 and $65 \%$ received treatment in 2007; whereas in Magila, $40 \%$ received treatment in 2004, 43\% received treatment in 2006 and 70\% received treatment in 2007.

\section{Uptake of drugs among adults in Pangani and Muheza districts, 2008-2010}

In July-August 2011, 118 semi-structured interviews were undertaken with a random sample of adults in Mwembeni, Pangani district, to assess the proportion of adults that had received ivermectin and albendazole for the treatment and prevention of lymphatic filariasis since 2007. As indicated in Table 3, the self-reported uptake of drugs was below $50 \%$ for the period 2008 to 2010 . A brief follow-up survey was also carried out in Jaira village. Taking a sample of randomly selected households near the trading centre, seventeen adults were interviewed, with $70 \%$ of them stating they had received the tablets. Follow-up research was also undertaken in Kigombe town and surrounding villages during this time. One hundred and forty-four semi-structured interviews were undertaken and Table 3 shows that the self-reported uptake of drugs remained below $50 \%$ from 2008 to 2010 . 
Table 2. Self-reported drug uptake for the treatment and prevention of lymphatic filariasis among adults in Muheza district, Tanga region, 2004-2007

\begin{tabular}{lccc}
\hline Village & 2004 & 2006 & 2007 \\
\hline Kigombe $^{\mathrm{a}}, N=146$ & $68(47 \%)$ & $66(45 \%)$ & $32(22 \%)$ \\
Bwembwera, $N=51$ & $24(47 \%)$ & $35(69 \%)$ & $33(65 \%)$ \\
Magila, $N=30$ & $12(40 \%)$ & $13(43 \%)$ & $21(70 \%)$ \\
\hline
\end{tabular}

${ }^{a}$ Kigombe includes Kigombe East and Kigombe West. Kigombe East includes the sub-villages of Sinawe, Gawani and Jitingeni and Kigombe West includes the sub-villages of Ndone and Mchangani.

Table 3. Self-reported drug uptake for the treatment and prevention of lymphatic filariasis among adults in Mwembeni, Pangani district, and Kigombe, Muheza district, 2008-2010

\begin{tabular}{lccc}
\hline Village & 2008 & 2009 & 2010 \\
\hline Mwembeni, $N=118$ & $26(22 \%)$ & $45(38 \%)$ & $56(48 \%)$ \\
Kigombe, $N=144$ & $45(31 \%)$ & $57(40 \%)$ & $49(34 \%)$ \\
\hline
\end{tabular}

Official district statistics on the uptake of drugs in Pangani and Muheza districts, 2004-2010

Official statistics submitted to the Ministry of Health from Pangani district differ from the information recorded in the Ministry of Health village drug distribution registers. That is, the overall uptake of drugs for lymphatic filariasis among adults and children more than five years old was reported to be $67.6 \%$ in $2004,78 \%$ in 2006 , $76.5 \%$ in 2007 and $75.2 \%$ in 2010 . Aware of the possibility that these aggregate figures may reflect much higher levels of drug uptake in other parts of the district, a decision was made in 2007 to go through all the available official village-based, drug distribution registers for Pangani district in order to double-check the accuracy of the official figures. In addition to the registers for Mwembeni and Jaira, registers were found for six of the 33 villages that constitute Pangani district. These villages were: Barabani, Chakaloboko, Mahakamani, Boza, Kimanga and Msaraza Bushiri. Not all registers for these villages were found to be complete for all three recorded rounds of drug distribution, but according to the registers available, drug uptake fell short of the sustained high coverage levels that are required to eliminate lymphatic filariasis. To be more specific, the uptake of drugs among the 4755 adults and children listed in the available registers as eligible for treatment in 2004 ranged from $49 \%$ in one village to $93 \%$ in another village, and the average uptake for all eight villages was $65 \%$. However, the uptake of drugs declined in all villages except one in 2006 . That is, uptake ranged from $81 \%$ to $35 \%$, and the average uptake among the 7823 adults and children listed as being eligible for treatment was $46 \%$. In 2007 , there were further declines in the majority of villages. Uptake ranged from $81 \%$ in one village to $7 \%$ in another village and the average uptake was 34\% among the 6436 adults and children listed as being eligible for treatment. 
The average figure for 2004 was thus very similar to that in the officially submitted report, but the high drug uptake reported in 2006 and 2007 in the official records submitted to the Ministry of Health did not correspond with the drug uptake data recorded in the village registers. While it is possible that the uptake of drugs is higher in other parts of Pangani district, this is an unlikely scenario. Many of the villages for whom drug distribution registers could not be found were located south of Pangani town. This part of the district is often inaccessible to district staff as it involves crossing the Pangani River by a ferry that is prone to mechanical breakdowns. Technical difficulties aside, budgetary constraints at district headquarters restrict the frequency with which staff can visit villages and facilitate the distribution of drugs - not least because many of the villages are located a considerable distance south of the river. As a result, difficulties go unnoticed and tend to increase, rather than decrease, over time. (These difficulties are discussed further on in this article.)

It was much harder to elicit comparable data about the uptake of drugs in Muheza district. In 2007 and 2011, considerable efforts were made to talk to district officials in Muheza as well as associated officials at a ward, village and sub-village level, but no Ministry of Health registers could be located in 2007, and only a small number could be located in 2011. In addition, it was difficult to make much sense of the information presented in the registers that could be located as they only provided a list of the names of people that had received treatment in 2010. In other words, in common with the registers located in Mwembeni in 2011, it was not possible to use the information to assess the proportion of people in any one village that had received treatment.

Nevertheless, summary statistics compiled at a district level (and subsequently presented as part of a regional report submitted to the Ministry of Health in Dar es Salaam in 2009), recorded an uptake of drugs in the district of $81 \%$ in $2006,76 \%$ in 2007 and $81 \%$ in 2008. The neglected tropical diseases co-ordinator for Muheza district also reported coverage of $83 \%$ in 2009 and $83 \%$ in 2010 - whilst acknowledging that the uptake of drugs was less in Kigombe as official returns suggested an uptake of 69\% in 2009 and 65\% in 2010 (personal communication, August 2011). While these figures are lower than the $100 \%$ uptake reported to the research team by a district official in Muheza in July 2007, they are still much higher than those recorded in the course of interviewing randomly selected adults at selected villages in Muheza district.

\section{Assessing the accuracy of data recording the uptake of drugs}

Discrepancies between the figures derived from semi-structured interviews, the official district figures, and the figures in the village-based registers raise important questions about the relative merits of the methods employed to elicit information on drug uptake. With respect to data arising from semi-structured interviews, is it really possible for large numbers of adults to accurately remember whether or not they have received a particular combination of drugs over an extended period of time? Is it possible that some informants muddle up the years that they received them and the years that they did not? Is it appropriate to assume that informants receiving drugs during MDA actually swallowed them? Whatever is done to alleviate anxieties and ensure that those being interviewed recount events as accurately as possible, is it possible for informants to try and second-guess the 'correct' answer to be polite or to just make the researchers leave them alone? 
Identical questions emerged whilst undertaking research on social responses to MDA for the treatment of schistosomiasis and soil-transmitted helminths in northern and south-eastern Uganda (Parker et al., 2008, 2012; Parker \& Allen, 2011). Here it was found that those interviewed clearly recalled treatment, partly because praziquantel tablets, which are used to treat schistosomiasis, are unusually large, pungent and unpalatable. In addition, the free distribution of biomedical drugs to treat adults is a rarity and not something easily forgotten. Indeed, it is widely commented on and the issue is less whether or not people remember, and more whether or not they are willing to say what happened to the drugs once they had received them. In some cases it became clear that instead of swallowing them immediately, they had kept all or some of their dose for future use if they felt ill, or to give to relatives and friends.

The situation was found to be slightly different with respect to MDA for lymphatic filariasis in coastal Tanzania, not least because the drug, ivermectin, is small, easy to swallow and does not have an unpleasant smell. Albendazole is equally straightforward to consume. Nevertheless, few people struggled to recall whether or not they had received free treatment - partly because it was so unusual to offer free medicines to adults and partly because it was considered to be very strange indeed to ask all adults to swallow medication, irrespective of whether or not they felt ill. In fact, the vast majority of people interviewed were remarkably forthcoming about their reasons for accepting or rejecting treatment and, more often than not, they asked pertinent questions about the rationale for the control programme that shed further light on why, for example, some people accepted treatment in the early years of the programme and subsequently declined treatment; while others declined treatment but subsequently accepted treatment for one or two years, before deciding to reject treatment again.

In general, data recording the uptake of drugs from semi-structured interviews undertaken at randomly selected households are, in most cases, likely to more accurately convey the proportion of adults that received the tablets than the data embedded in the official Ministry of Health registers by village-based drug distributors. There are several reasons for this. First, villages can be quite dispersed and drug distributors were sometimes found to be unaware of all people living in the village. Second, social divisions within a village can often affect the kind of people recorded. In Mwembeni, for example, the long-standing differences between Muslims and Christians were found to have influenced the number of people registered. Some of the resident Christian Makonde were dismissed as 'refugees', or even 'not real people'. Third, short-cuts are often taken in the time-consuming job of handing out tablets. Close discussion with the distributors and people receiving drugs revealed that the protocol of observing consumption was often not followed. In several instances, it was found to have been largely set aside, in a similar manner to the practice noted above with respect to praziquantel distribution in Uganda. As a result, it is not known if those who are recorded as having taken the drugs have actually swallowed them. Thus, drug uptake data in the village-based distribution registers may overestimate, rather than underestimate, actual consumption.

This is not to suggest that the data in the Ministry of Health registers are always inaccurate. On the contrary, some drug distributors went to great lengths to carefully record the names, ages and sex of the people they gave drugs to. However, the consistency of registration between distributors was found to vary; and it was often impossible to judge the quality of the recorded data without checking them. In most 
cases, they provided, at best, a partial picture of the proportion of people in a specific geographical area that had received treatment.

A more worrying issue is that the summary statistics compiled at a district level on drug uptake suggest much higher levels of drug uptake than data eliciting drug uptake among adults in the course of interviews. While the latter data only refer to adults, it is likely that they provide a useful proxy of the extent to which MDA programmes reach adults and children at the selected study sites. The reasons are straightforward: mass treatment occurs through village drug distributors, rather than school teachers; and if adults are willing to receive (and possibly consume) tablets for themselves, then they are almost always willing to receive tablets for their children. Similarly, if they reject medication for themselves, then they are likely to reject treatment for their children. It is also worth noting that in those instances in 2004 and 2005 when village drug distributors recorded the numbers of people living in a village on a household-byhousehold basis in the Ministry of Health registers and whether or not each person had received drugs, there was a similar discrepancy - with drug uptake being much lower in the registers than the aggregate figures recorded at a district level. Senior district officials, when asked to comment on the discrepancies, were quick to set aside the higher figures. One of them disarmingly observed: 'people are just sitting down and cooking the numbers'. He went on to express frustration with the treatment programme by saying 'this programme has no legs'. This was a literal reference to the shortage of fuel and other resources enabling staff to spend the requisite time in villages explaining the rationale for mass treatment. He was, in short, not surprised by the lower drug uptake figures emerging from field-based research. This view was shared by others working at district headquarters. In short, there is no doubt that the uptake of drugs is low at the selected study sites (and rates of take-up in other highly endemic coastal villages in Pangani and Muheze districts are likely to be similar). Why is this the case?

\section{Why is the uptake of drugs for the treatment and prevention of lymphatic filariasis low?}

The low uptake of drugs cannot be attributed to a lack of awareness of the signs and symptoms of lymphatic filariasis. While there is no Swahili word for the disease, two of the major clinically recognized signs of infection, swollen scrotums and swollen limbs, are perceived locally as separate afflictions, with the former being referred to as mabusha and the latter as matende. Both are feared, even if they are not considered as life-threatening as malaria or HIV/AIDS. Adults participating in the surveys on drug uptake were asked what they thought were the major illnesses affecting local people. Malaria was cited by far the most frequently. It was mentioned by $64 \%$ of those interviewed at study sites in Pangani and 78\% of those interviewed at study sites in Muheza, whereas HIV/AIDS was mentioned by $29 \%$ of adults in Pangani district and $19 \%$ of adults in Muheza district. Mabusha was mentioned by $27 \%$ and $24 \%$ in Pangani and Muheza districts respectively and matende by $12 \%$ and $15 \%$ - although 'muscle or leg pain' was also mentioned by $26 \%$ and $20 \%$ of adults respectively in these two districts.

In more open-ended discussions, mabusha, in particular, was spoken about as a constant threat for men. Typically, statements were made about it generating feelings of shame and misery. For example, a 27-year-old man from Jaira village explained that 
mabusha is a torturing disease: '[it] makes you sad, unhappy, everyday' (all such quotes in the article have been translated from Swahili). Another man, aged 31, and also from Jaira said, 'I feel so ashamed, especially with those I respect. . . I I have access to women but they always say: "I don't want you, because you will give me the infection".' Others, including a 52-year-old man from Kigombe, complained that 'people talk about you when you are not there. It makes you fearful and anxious ... No woman will want you if you have mabusha ... unless they are a witch and they want your money....

In some cases, the distress, misery and desperation was so intense that men tried to operate on themselves. In 2007, for example, a 40-year-old man from Mwembeni told us that he had operated on himself twice to try and drain the fluid from his scrotum. Tragically, he died in 2008, reportedly whilst trying to perform the operation on himself for a third time. Attitudes to matende tended to be more stoical, but the worst cases observed were shocking, with afflicted individuals, mostly women, being hidden away out of site.

Given that mabusha and matende are widely recognized to cause sickness and suffering, one might assume that the provision of free treatment would be welcomed. Why, then, are the majority of adults not taking the drugs? Are they being distributed appropriately? If so, does it follow that adults are actively rejecting treatment? The rest of this section demonstrates that there is no single explanation for the low uptake of drugs. Rather, a combination of social, economic and political reasons explain the low uptake of drugs at the different study sites. These include: fear of treatment (attributable, in part, to a lack of trust in international aid and a questioning of the motives behind the distribution); divergence between biomedical and local understandings of lymphatic filariasis; insufficient and inadequate communication about the rationale for mass treatment; and too great a reliance upon too few volunteers to distribute drugs within villages. These issues are discussed in turn.

\section{Fear of treatment}

Mass drug administration for mabusha and matende generated anxiety and scepticism among the majority of adults, with informants questioning the motives behind the free distribution of drugs by the Tanzanian government and international agencies. A young man from Jaira, for example, said: 'There is something strange going on. If the government want to help us, they should distribute malaria drugs for free, not matende and mabusha.' Similarly, a 40-year-old man from Mwembeni commented that, 'there is no sign [on the drug] that it is for mabusha or matende ... you have to trust in the government to swallow the tablets ... trust matters a lot. If you don't trust them, you can't swallow the drug ... the programme doesn't come with enough knowledge.' Meanwhile, in Kigombe, a man in his 50s justified not taking the tablets in the following way: 'In this village we cry for water ... they haven't brought water for free, but they've brought drugs for free. Why? These free drugs have to be for an experiment ... that is why I reject them.' These kinds of comments were typical in locations with low drug uptake and highlight the fact that the rationale for distributing tablets for mabusha and matende, free of charge, was poorly understood. Acutely aware that clinic-based biomedical practitioners tend to diagnose infections before administering drugs, and 
confused why such an approach was deemed unnecessary by the Tanzanian government in this case, rumours circulated about the 'real' intentions behind the free distribution.

A very prevalent concern was the idea that the drugs had been designed to reduce population growth. As one man in Kigombe put it: 'they are lying about this drug. It is not for mabusha or matende ... [it is] a family controlling pill .... Younger men discussing this issue tended to emphasize the idea that the tablets reduced their sexual energy. For example, at a village meeting in Mwembeni, a young man summarized the views of others when he said, 'They are afraid ... they say if you are infected [and you] take the drug then your penis will never erect again.' It was a view echoed at a comparable group discussion at Kigombe, where a man in his mid-30s proclaimed that '[People from the] rich countries send us this drug to reduce our malehood energy and to make us infertile, because the wazungu (white people) were fed up giving us help every day.' For others, the focus was more on the way the tablets might be intended to prevent conception, a view that was probably supported by the reluctance of some drug distributors to give the tablets to women who said they were pregnant. For example, a man in his 60s living in Mwembeni commenting on local views said, 'They say if you take the drug, you will never give birth ... they believe the government has failed to convince them to enter into family planning.' Women were particularly likely to say something comparable. Thus, a young woman from Kigombe commented that, 'These drugs are coming from Europe. We know women in Europe have two children and their intention is to make Africans like Europeans. They think we can't manage so many children, that we can't provide proper education, health care and home environment.'

Concerns about infertility were also connected with the experiences of some of those who had swallowed the drugs. There was considerable discussion about sideeffects. A man in his 30s from Mwembeni, for example, described how he took the tablets in 2006 and experienced a strong fever with rashes. He went on to say that he did not take the drug again as he feared the side-effects. Others expressed concern that the drugs exacerbated existing symptoms, and even infected people with mabusha and matende. A woman from Kigombe, for example, said that she did not take the drugs in 2004 as she was pregnant. She subsequently rejected treatment in 2006 and 2007 as she had '... seen people infected by those drugs in $2004 \ldots$ there were some who got body pain and fever. If I took those drugs, I would be infected too .... In a similar vein, an elderly woman from Mwembeni said: 'They were afraid that if they took the tablets the busha would get bigger,' and a man from Kigombe said: 'They are afraid that if they take the drug they will get matende or mabusha ...'. There were, in addition, stories that were even more alarming. A young man from Mwembeni, for example, said: 'they fear the drugs will kill them ...'. He was not the only one to mention this. He went on to explain that, 'most people do not receive reliable information and knowledge about the drugs.'

These last remarks relate to prevalent doubts about drug efficacy. This is hardly surprising as few, if any, people were aware that it was possible to be infected and asymptomatic and almost all of those with mabusha and/or matende complained that the drugs were not making much or any difference. For example, a man in his $60 \mathrm{~s}$ from Kigombe had lived with mabusha since his mid-40s and took the treatment in 2004, 2006 and 2007, but declined free treatment in subsequent distributions. He explained that, 'The drugs make no difference ... the weight of my testicles disturbs 
me.' His experience was shared by a younger man who had accepted treatment in 2004, but subsequently refused it. He complained: 'I have hernia and mabusha. When they announced the treatment, they said it would cure me. I took it, but it didn't work. So why take it again? Some other people I know took the drug and then got mabusha, so they didn't take it again either.' These perspectives were widely shared. A woman in her 30s with matende who had also taken the drugs only once summed up attitudes when she said: 'We are getting no relief from the medicine ... the drugs are not working.'

\section{Divergence between biomedical understandings of lymphatic filariasis and local understandings of mabusha and matende}

Widespread fears, anxieties and rumours emerge, in part, from villagers making their own empirical observations about the side-effects associated with treatment and the limited visible efficacy of the drugs. They also draw attention to the disjuncture between biomedical understandings and responses to lymphatic filariasis and local understandings and responses to mabusha and matende, which are perceived locally as entirely separate afflictions. To quote a local healer (mganga) from Pangani: 'Some people have both mabusha and matende ... but they don't come simultaneously. The fact that mabusha can be operated on and matende cannot be operated on, proves that they are different diseases ...'.

The majority of people do not attribute a single cause to either mabusha or matende. Indeed, it is not unusual for three or four causes to be mentioned, and for each to be accorded equal weight. This sub-section discusses local understandings and responses to mabusha and matende. In so doing, it becomes apparent that these locally recognized afflictions are understood in a context where virtually everyone, including health care workers at government dispensaries and health centres, draws upon a pluralistic approach to diagnosis and treatment to understand sickness and misfortune.

It is also worth noting that discussions about mabusha, and to a lesser extent matende, can be infused with moral overtones, with spirit mediums sometimes threatening those who are thought to be behaving badly by saying that they will 'throw a busha'. In Madanga division, for example, there was a ceremony associated with the local possession cult called Mwaka Koga, part of which was held at a sacred well on the outskirts of a village. People gathered spoke to the spirits in the well. At one point in the ceremony, the spirit medium said: 'Protect us, cure us and treat us so that we can be healthy and have peace and happiness in our lives... There are some ... who see those who come to us as barbaric, uncivilized and ignorant; and they see themselves as educated, civilized and more religious ... They only believe in one God ... [To them we say:] give them bushas and matende and never cure them, until they come here and beg for forgiveness.'

Local understandings and responses to mabusha. The majority of adults are unaware of any relationship between mosquitoes and mabusha. Of the 335 adults interviewed whilst undertaking drug uptake surveys in Pangani and Muheza districts in 2007, just $11 \%$ attributed mabusha solely to the bites of mosquitoes. While a small proportion of informants attributed mabusha to the bites of mosquitoes and other causes (notably acts of witchcraft, sex, hernia, dimensions of diet, acts of God), the vast majority of 
informants either did not mention mosquitoes as a possible cause or remained unconvinced about their role in transmission. On one occasion, during a village meeting, a female sub-village leader took issue with the biomedical explanation being put forward by a health worker about the aetiology of mabusha and said: 'we can fight to the death, but you will never get me to believe that it is not caused by sex with a menstruating woman!'

The reference to sex is important here. It highlights the fact that mabusha is widely talked about as a sexually transmitted disease. For example, a Christian man from Mwembeni explained that, 'The blood is full of vidudu (micro-organisms) ... God created menstruation to clean the woman from vidudu ... but these vidudu get into a man if they have sex when she is bleeding [and it leads to mabusha].' A Muslim elder added, 'the vidudu in the blood passes into the penis and it can lead to mabusha.' Others agreed with this point, but emphasized that it was only possible to get mabusha from a menstruating woman if the sex occurred outside of marriage. Thus, a woman from Mwembeni said, 'If you steal someone's wife, who is protected by the healer, then you get mabusha with vidonda (severe rashes on the penis), and a man from Kigombe said, 'if you have sex with a prostitute that is menstruating, you can get mabusha ... you see, they will never tell you that they are menstruating as they want the money.'

In addition to sexual intercourse, other explanations for mabusha include one or more of the following: a lack of food, eating too many coconuts and/or drinking immature coconut juice, being bitten by mosquitoes and acts of God. Hernia, too, is closely associated with the occurrence of mabusha. A 62-year-old male, for example, commented: 'A hernia is a disease. Inside the hernia, there are intestines which fall down towards the testicles. Oil or water from inside the intestines pass down into the testicles and make a busha.' Similarly, a local mganga said: 'it catches you at the waist ... the muscles around the waist can squeeze the hernia, and the fluid goes into the testicles,' and a young man, speaking at a village meeting, said: 'if you have a hernia, your testicles swell ... but it doesn't mean that it's hydrocele [although] most people think that it's not possible to have a hernia and not have busha ...'.

Ideas about witchcraft also play a central role in local understandings of the aetiology of mabusha. Here, it is helpful to note that different kinds of mabusha are recognized locally, with some kinds being more overtly linked to acts of witchcraft than other kinds. Two of the most widely recognized kinds of mabusha are: busha la maji and busha la mafuta. Busha la maji is thought to be effectively treated by surgery at hospital as the water can be drained away, whereas busha la mafuta is not thought to be treatable in a hospital setting. As one 70 -year-old male said: '. . . even if the fatty oil is scraped out, it just fills up again ...'. Others spoke of busha la mkoba and busha la $u c h a w i$. With respect to busha la mkoba, it is interesting to note that the word mkoba is Swahili for woman's handbag and that witches are sometimes thought to carry the tools of their craft in their testicles. As one mganga said: 'mgangas who hide their tools in a mkoba are not mgangas. They are witches, but they exist.' Busha la uchawi translates as 'bewitching busha' and a local mganga described it in this way: '... in the village, if you have a conflict with a man in the village, he will bewitch you ... there are some diseases that cannot be cured by biomedicine, only by herbs. Diseases like busha la uchawi cannot be treated at the hospital .... 
Many local mgangas and other villagers talked about their ability to make mabusha. A 35-year-old woman from Kigombe, for example, said: 'If you have a quarrel with a person, they can take revenge and punish you by making mabusha ... there is nothing you can do ... no drugs can help.' It is important to note, however, that several mgangas did not concur with the view that mgangas were capable of 'throwing a busha'. As one mganga from Madanga pointed out: 'Mgangas sometimes say they can 'throw a busha', but this is not the work of a mganga. It is the work of a mchawi (witch/ sorcerer). The work of mgangas is to cure, not to make sickness.'

Whatever the role of mgangas, it became apparent that the majority of informants linked the occurrence of some kinds of mabusha to acts of witchcraft, with the type of mabusha influencing the type of treatment sought. Moreover, mgangas are usually consulted to determine the cause of mabusha, and if it is deemed to be busha la mafuta, then biomedical treatment is avoided. Busha la maji is thought to be treated by doctors and most mgangas recommend biomedical treatment, as they do not think they can treat anything but the early signs of mabusha such as fever. It is important to note, however, that some informants did not differentiate between types of mabusha. Instead, they advocated biomedical treatment in all cases. For example, a 63-year-old Christian Makonde in Mwembeni remarked that: 'It is a shameful disease and you can't live with it ... you must be operated on as quickly as possible ... No local mganga operates on mabusha.' Similarly, a Muslim man from Kigombe observed that, 'The best [thing to do] is to go to hospital for an operation ... it is difficult for a mganga to treat mabusha because he has no equipment and no knowledge of what to do.'

In general, it was found that there is considerable demand for surgical treatment. However, many men do not go down this route as it normally costs approximately 100,000 Tanzanian Shillings (about $£ 40.00$ ) and few have the necessary income to pay for it. An exception is when the operations have occasionally been offered free. In 2007, for example, names of individuals who stated that they had hydroceles and wanted an operation but could not pay for it were collected at the field sites. Their names were then passed on to district health staff. The TNLFEP was additionally alerted to the very large number of cases. Two hundred operations were subsequently carried out on some of these men as well as other individuals at a surgical camp in Pangani district with special funding in 2008 (Malecela, 2009a, p. 55; personal communication by email on October 19th 2007). Partly as a consequence, scores of others needing operations made themselves known to the research team in 2011 (roughly 1:10 men in Mwembeni), although many stated that, even if the operations are free, they would find it hard to be treated, because they could not afford not to work for six months after the operation. To quote a 30-year-old man from Mwembeni: '[They tell us] you can't do masculine (i.e. heavy) jobs for six months, but how will our children eat then? What we do to earn a life is tough work ... if you rest for six months, your children will die.'

Others are afraid to be operated on. One man, reflecting on the fact that his friend showed no inclination to get treatment from the hospital, said: 'he has decided to tie a tight rope around his testicles to try and prevent them from swelling.' Others are afraid that they will die if they are operated on. This fear relates to anxiety as to whether they have busha la maji or busha la mafuta as the latter needs to be treated by a mganga and, more significantly, treatment at a hospital is not only inappropriate, but can 
lead to death. To quote a mganga from Mwembeni: 'Some mabusha is caused by $u c h a w i$... if you go to a hospital for an operation and it is caused by uchawi, you will die immediately.'

Local understandings and responses to matende. In common with mabusha, villagers attributed matende to a number of different causes. It was not unusual for several explanations to exist side-by-side and for each one to be deemed of equal importance. Matende, for example, was often said to be an inherited condition as well as being caused by mgonzo fever and/or the bite of a mosquito. In contrast to mabusha, the majority of adults at all study sites said that they did not know what caused matende, but mgonzo fever was widely recognized as an early sign of matende. It is very different to the fevers associated with malaria, and one male informant described it in the following way: 'Mgonzo is a fever, a very strong fever. When it catches you, you will be seriously ill, to the extent that you urinate unconsciously, shiver and speak nonsense. When the fever comes down, the leg starts to swell. Two or three days later, the swelling goes down and the skin peels off. He or she might be OK for a year [but] then they will experience the fever again, until it becomes tende ... It is best treated with a painkiller.' Similarly, a Muslim woman from Kigombe East said: 'Homa mgonzo can lead to matende. [It] is very strong ... you feel very, very cold and shiver all over ... the fever goes into the body's muscles and the effect of this is that it goes into the legs and feet and leads to swelling. Some people can get swellings in their arms too.'

Various causes are attributed to the occurrence of mgonzo, including open wounds and sexual intercourse. The logic is clear: 'I cut my foot while I was farming and, soon afterwards, I got mgonzo. It was not [an ordinary] homa (fever) as the head does not hurt if you have homa and my head was hurting.... Some people also get matende from mosquitoes, but I didn't,' (Muslim woman from Kigombe who has had matende for many years); 'Mgonzo is a strong fever that leads to a swelling of the legs. I get this fever once a year and so does my wife. Now her leg is starting to swell ... I think I gave it to her through sexual intercourse,' (Christian Makonde man from Mwembeni).

In contrast to mabusha, a sizeable number of informants mentioned mosquitoes as the sole cause of matende (for example, 37\% in Kigombe West in 2007). Explanations for how mosquitoes transmit matende included the following: 'I heard that mosquitoes cause matende and I think it is true ... maybe the mosquito has poison inside it and this is why the legs swell,' (a man in his 50s from Kigombe East); 'There is a mosquito called Culex ... when that mosquito bites someone with matende and then bites you, you will get matende,' (a man in his 80 s from Kigombe West).

Inter-personal and metaphysical explanations also featured in peoples' narratives. As noted, this applies more to mabusha than matende. Nevertheless, like any other affliction, such interpretations were a possible explanation, often in combination with others. Here are a few examples: 'My mother gave birth to 12 children. People were jealous of her and they made uchawi (witchcraft) to give her matende,' (60-year-old man from Mwembeni); 'When you have a conflict with someone, that person will go to a local mganga and make matende by using spiritual force,' (34-year-old woman from Kigombe); 'Mchango ... it is in your stomach, it eats the food you take in. It is like a worm. There are good mchangi and bad mchangi. Bad mchango causes minyoo, busha 
and matende, together with safura (hookworm),' (65-year-old man from Kigombe); 'I got matende by stepping over uchawi (witchcraft),' (56-year-old woman from Mwembeni).

Others emphasized the fact that matende was an inherited condition. Here are statements made at a group discussion: 'I think it is caused by a mosquito, but many people think it is inherited.' 'If your father has it, then it can be passed on to sons, daughters, grandchildren ... like having twins.' 'If the parent has twins, then anyone in the family can have them.' 'My wife has matende in her right leg and her mother suffers from it too. She inherited the condition.'

Although it is less common with respect to matende to assert a witchcraft explanation, the view is sometimes expressed that it is possible to differentiate between the type of matende caused by a mosquito and the type of matende caused by witchcraft. The following quotes are a good examples of the range of perspectives frequently exchanged among groups of people sitting together with an afflicted person and commenting on the problem: 'There is no treatment for 'normal matende', but witch matende can be treated by mgangas (local healers).' 'Women can stop matende by wearing several pairs of underwear to stop it spreading.' 'Inside the matende is oil ... if you go to the hospital, they can remove the oil and the swelling will come down.' 'The normal matende can be cured, and the swelling goes down, after treatment at the hospital. The other kind does not go down with hospital treatment.'

\section{Limited and ineffective communication}

It has been argued that social mobilization and advocacy is a key component of effective MDA for lymphatic filariasis in Tanzania (Malecela et al., 2008, p. 117). This is said to comprise everything from radio spots to posters, film shows and the use of mobile megaphones. All this activity is reported to occur in Swahili and to have been incorporated into a set of lymphatic filariasis control 'programme principles'. While these activities may well have occurred at some locations, it is also the case that they either have not occurred or they have had a minimal effect at the field sites where this research occurred. As a result, very few people understood the rationale for distributing drugs, free of charge, to adults and children. Staff employed at health centres, as well as village-based drug distributors, were thus genuinely confused as to whether the drugs were designed to prevent infection or treat existing infections. With few exceptions, they had no idea that it was possible to be infected and asymptomatic and they were at a loss about how to answer frequently posed questions. These included variations of the following, all of which were posed at village meetings and/or during interviews in 2007 and 2011:

Why should I take the tablets when I feel well? Why do the tablets need to be taken by everyone once a year? How can one drug protect someone from two different afflictions? Why should I take the tablets again as I took the tablets last year and I still feel ill? Why should I take the drugs as I do not have mabusha or matende? I took the drugs last year as I have mabusha, but the swelling did not go down. Why should I take them again? How can these drugs prevent mabusha when it is caused by witches and spirits? Why is there an operation for mabusha, but not matende? Why do some people get fevers and others swollen bodies after swallowing the tablets? Why do drug distributors allocate the number of tablets according to height rather than weight? Why are Europeans manufacturing tablets for mabusha and matende when they do not suffer from these diseases? 
At all sites there was an eagerness to engage in debate and discussion about these issues, and innumerable complaints that the drugs were being given out by local distributors who could not explain how they worked or exactly what they were for. As one young woman from Kigombe put it: 'there is no information about why you should take the drugs, what the drugs are for and other necessary information to convince people to take the drugs.' With so many unanswered questions, it is hardly surprising that people questioned the merits of mass treatment.

What appears to be an unwillingness or an incapacity to engage with local concerns of these kinds, and specifically to address matters such as pluralistic approaches to aetiology and treatment in health education materials and training of distributors, is by no means unique to staff working for the National Programme to Control Neglected Tropical Diseases in Tanzania (see, for example, research on the control of schistosomiasis and soil-transmitted helminths in Uganda by Parker et al. (2008) and Parker \& Allen (2011), and research on malaria by Hausmann Muela et al. in Tanzania $(1998,2002))$. It does, however, have unfortunate consequences as it ends up confirming, rather than refuting, existing outlooks and fuels anxieties about the merits of swallowing drugs provided by international donors and distributed through government channels. That said, it would be a great mistake to assume that more extensive and sophisticated communication will be sufficient to improve drug uptake. The current system of rolling out free drugs relies upon voluntary labour to run the programme and this, too, is problematic. The next section discusses this issue.

\section{Too great a reliance on voluntary drug distributors}

Village health workers, otherwise known as the 'community's own resource persons' (CORPS) take responsibility for distributing drugs for the treatment of mabusha and matende (Malecela et al., 2009b). They are trained through a cascade system. That is, health workers at a national level train health workers at a regional level; regional staff train staff working at a district level; and district staff train those working at a ward and village level (Malecela et al., 2008). Village drug distributors are not paid for the time they spend handing out drugs within their villages, but they receive a small 'sitting allowance' for attending training sessions. While positive statements have been made about the effectiveness and efficiency of the cascade system (Malecela et al., 2008, 2009b), observations and discussions with health workers and other villagers suggest that the current system does not always run smoothly.

In particular, it overlooks the fact that some villages cover significant geographical areas and there are often significant constraints preventing distributors from taking the time to contact those living on the outer reaches of their village. To walk from home to home, persuading individuals with whom there is little social connection, requires a big commitment. This is expected to occur in addition to a normal day's work, and may need to be done repeatedly, because many individuals may be absent, perhaps fishing or farming or visiting relatives. Crucially, the reliance upon a small number of adults to distribute drugs within each village also assumes that a sense of goodwill and concern extends to all residents equally. In many places, this is not the case.

In Mwembeni, for example, the Makonde are, in social and political terms, much more marginal than their Muslim neighbours. They are often referred to as kafir. As 
a result, many of them are not even recorded in the village register. In addition, it became apparent that by 2010 a parallel system of drug distribution had emerged. That is, two Muslims were taking responsibility for distributing drugs throughout the village. Christian Makonde living reasonably close to the centre of the village were told to come to a central location to collect drugs, but those living 'far' from the centre were not informed of the treatment. A 55-year-old Makonde man, living on the outskirts of the village, summed up the situation when he revealed that he had never heard about the free provision of drugs as: 'the only information we get is when we have to contribute something ... the other news is not delivered.' By contrast, many of the friends, neighbours and relatives of the drug distributors were being given drugs in their own houses. Somewhat similar issues were also noted in Kigombe, where divisions between political parties, between Muslim factions and between Muslims and Christians all affected distribution activities. As in Mwembeni, many Christians complained that they were not informed about the drug distributions. Moreover, in 2007, one of the imams was reported to have openly opposed distribution activities to his followers, and the distributors lacked the authority or knowledge to challenge him.

Such diverse (and often very locally specific) divisions in what are perceived externally as homogeneous communities obviously affect drug distribution. Indeed, close scrutiny of a programme like Tanzania's National Lymphatic Filariasis Elimination Programme makes manifest social hierarchies and fissures. They become particularly clear in ethnographic research, though they may be hard to enumerate. Although efforts were made to see if it was possible to discern consistent patterns of treatment exclusion in the data that were collected during semi-structured interviews on drug uptake, this did not prove particularly insightful. Political affiliation, for example, was too sensitive an issue to be asked in all interviews, and it was sometimes difficult to assess the accuracy of answers when they were forthcoming. Systematic effects of the manifest conflicts and tensions in the Muslim population were similarly hard to gauge and quantify. However, with respect to drug distributers' coverage of resident Christians, it was possible to make a basic assessment in Mwembeni. Here, there were some Christians living near the primary school, not far from the village centre, or who had children at the school. They tended to be offered tablets. It was those residing at the periphery of the village that were omitted. Also, a general bias towards offering tablets to Muslims in preference to Christians was discernible in the self-reported uptake data: between 2004 and 2007, $53 \%$ of Muslim adults reported taking the tablets in Mwembeni, and $48 \%$ of Christians. Ethnographic research on this and other issues revealed that there were marked differences of attitude and commitment among drug distributors. Observations and discussions strongly indicated that it was the most marginal that end up being excluded from the offer of treatment.

\section{Why is self-reported drug uptake higher at some locations?}

It remains to be explained why self-reported drug uptake is higher in some places than others. The answer is relatively straightforward. It relates to levels of engagement with the target populations and resulting increased capacity of people to make informed choices. It has already been observed that the proximity of the official sentinel site near Tanga town at Kirare and the visits of medical staff and researchers explain a relatively 
high self-reported uptake rate, even if it is less than is necessary for long-term control or elimination of the disease. Similar rates were noted in this study, in Bwembwera and Magila in Muheza district and at the small trading centre of Jaira in Pangani district.

The case of Jaira was discussed with district medical staff based at the hospital in Pangani town in 2011. The District Medical Officer commented that the improvement in self-reported drug take-up (from a low of $40 \%$ in 2007 to around $70 \%$ in 2010) must have been to do with the direct involvement of his staff. Some of his staff had been to Jaira at the time of distribution and had responded personally to the questions and concerns of the population. It was not possible to do so elsewhere due to lack of transport and lack of qualified personnel who might be deployed.

With respect to Bwembwera and Magila, the take-up rates of $68 \%$ in 2006 and $65 \%$ in 2007 in Bwembwera, and 70\% in 2007 in Magila, probably reflect their proximity to Muheza town and to Muheza hospital. It was found that in these locations knowledge about lymphatic filariasis and the rationale for mass treatment had been more adequately communicated than in locations near the coast. In addition, it was reported by informants that surgery had been made available to those men seeking it through an established system of referral, rather than the kind of ad hoc surgery camp that was run in Pangani in 2008. District medical staff additionally noted that higher rates of drug uptake near to Muheza town reflected the better training and larger number of drug distributors than was the case in more remote locations. They were well aware of the difference in levels of engagement within the district, and explained that they just did not have the resources to run a more effective operation at a distance from their base.

\section{Conclusion}

The research presented in this article is based upon fieldwork undertaken in northern coastal Tanzania. It demonstrates that the uptake of drugs at selected study sites in Pangani and Muheza districts falls short of the sustained high coverage levels required to eliminate lymphatic filariasis, and the prospect of eliminating the disease by 2020 with current strategies is remote. In broad terms, the findings presented in this article add to the worrying conclusions of Simonsen et al. (2010), who report that drug uptake at the nearby and closely studied sentinel surveillance site at Kirare, while higher than those reported at the study sites in this paper, is insufficient; and that MDA is having declining effects on disease control. In combination with research undertaken by Michael et al. (2004, 2008) and Gambhir et al. (2010), results presented here highlight the pressing need to fine-tune mass treatment programmes according to ecological, biological and social factors operating at a local level. The results also highlight the need for more adequate monitoring, recognizing that there are risks involved in sustaining MDA with partial coverage over time, including risks associated with drug resistance (McCarthy, 2005).

Elsewhere in the country, findings have been more encouraging. Considerable success, for example, has been reported in Zanzibar (Mohammed et al., 2006; Mohammed, 2008). Here, the prevalence of microfilariae has fallen from $17.8 \%$ and $7.2 \%$ to less than $2 \%$ at two sentinel surveillance sites, following five annual rounds of mass treatment. Where there are apparent successes of this kind, it would be helpful to know exactly why they 
have occurred. The present trend in the NTD literature, driven by target-orientated funding, is to assume they are inevitable. Explanations for the reported achievements in Zanzibar include sustained high MDA coverage of $70-80 \%$ over a five-year period, linked to the introduction of effective lymphoedema management programmes. It is probably also significant that the prevalence of microfilariae was initially lower than that recorded at Kirare. It is not clear, however, whether these lower levels were due to other vector control activities that may have been running in the vicinity for lymphatic filariasis and/or malaria or whether they reflect the relative affluence and ease with which Zanzibari populations can access public health interventions and other forms of biomedical care compared with populations in Tanga region on the mainland. Whatever the explanation(s), it is dangerous to simply assume that the results can be readily replicated. There are specific reasons why MDA works in some places and fails in others; and it is crucially important to know what these reasons are.

The mixed effects of MDA for lymphatic filariasis have specific aspects but in other ways are not unique. Mass distribution of drugs for other neglected tropical diseases faces comparable problems. In Tanzania, Hastings documented the uptake of ivermectin and albendazole for the treatment and prevention of onchocerciasis in Doma, Morogoro region, in 2007. Working with a $20 \%$ sample involving 150 randomly selected adults, her research suggested that uptake fell from $31 \%$ in 2004 to $29 \%$ in 2006 and $17 \%$ in 2007 (Hastings, personal communication). Wingate-Saul documented the uptake of the drug praziquantel for the treatment and prevention of infection with $S$. mansoni. Working in fourteen villages in Ukerewe Island, her research suggested that in 2007 drug uptake among adults ranged from $18 \%$ to $74 \%$, with the average uptake being $44 \%$ (Wingate-Saul, 2008). These rates are well below target levels, and it is not clear what effect they are having on the prevalence of infection. Meanwhile, a disturbing indicator of how local fears and rumours can spiral out of control are the violent riots that occurred in several locations during 2008 in response to MDA for the treatment and prevention of $S$. haematobium in schools. Hastings had to be rescued from her research location near Morogoro by armed Tanzanian police. Some teachers found distributing drugs were not so lucky and were beaten by angry mobs convinced that tablet distribution had sinister motives, such as population control (IRIN Humanitarian News and Analysis, 2008; Daily News Online Edition, 2008).

There are, of course, well documented accounts of social resistance to other top-down biomedical disease control programmes such as vaccination programmes to control polio in Nigeria (Yahya, 2010; Renne, 2011) and tetanus in Cameroon (Feldman-Savelsberg et al., 2000); as well as the provision of condoms to prevent the transmission of HIV/ AIDS in parts of Indonesia (Butt, 2005), Botswana (Heald, 2000) and South Africa (Niehaus \& Jonsson, 2005). With respect to neglected tropical diseases, there has also been some active resistance to treatment in Uganda, if not on the scale of the Tanzanian riots. These have been described in relation to MDA for schistosomiasis in north-west Uganda (Parker et al., 2008, 2012; Parker \& Allen, 2011).

How, then, should fears associated with the mass distribution of drugs for the treatment and prevention of lymphatic filariasis be addressed? It may be tempting for policymakers and planners to feel that the most effective way to respond to the low uptake of drugs for lymphatic filariasis is to continue to focus on narrow technical and logistical aspects of drug delivery as there is little they can do to counter rumours that the govern- 
ment and international agencies have hidden agendas that do not serve the interests of local people. This would be a mistake. However misplaced local fears and anxieties about free treatment actually are, they are also ideas that are widely held and have emerged from experiences and empirical observations. White (2000), reflecting on the persistence of vampire stories in Africa, and Geissler \& Pool (2006), analysing rumours associated with medical research projects in sub-Saharan Africa, have demonstrated the multiple ways in which stories and rumours articulate local understandings of the workings of power and knowledge.

Given that it is politically and economically neglected people who are mostly infected with neglected tropical diseases, it is hardly surprising that the targets of vertical MDA projects do not necessarily take the stated intentions of those running them at face value. Their concerns and questions need to be acknowledged and understood. There is a need for a real engagement with such populations, necessitating different kinds of local-level strategies. With respect to lymphatic filariasis, it is quixotic to imagine that MDA will work in isolation. A range of interventions are required, and social empowerment needs to be part of the mix. New ways have to be found to explain the rationale for mass drug administration; that mabusha and matende are signs of the same infection; that it is possible to be asymptomatic and infected with parasitic worms; that the drugs being provided will not necessarily reduce the swelling of those suffering from matende or mabusha; that the purpose of combining the drugs invermectin and albendazole is to prevent those who are infected but asymptomatic from developing clinical signs of infection; and that the drug albendazole also has the capacity to treat those suffering from other worms, notably soil-transmitted helminths. There has to be knowledge transfer for afflicted people to be able to make informed choices. As Allotey et al. (2010) note, the current emphasis on context-free, pathogen-focused NTD control is a return to 'magic bullet' medicine, and ignores the fact that vaccines and drugs do not cure neglect or poverty.

Perhaps the largest challenge of all is not how to win round the hearts and minds of those being targeted for treatment, but rather how to create a space whereby those engaged in developing policies at a global level feel able to acknowledge that the types of difficulties discussed in this paper are significant and that raising them is helpful and relevant for developing more effective strategies. Considerable institutional pressures mitigate against effective action, not least because intense competition for funding discourages critical thinking and analysis (Allen \& Parker, 2011, 2012). There is a tendency towards disingenuous dismissal of important information, both social and biological, and an overemphasis on quickly achieving optimistic goals. It has led to some questionable claims about what has already been achieved, and to some strongly worded responses to the kind of research presented here.

A global commitment to control or eliminate lymphatic filariasis and other neglected tropical diseases is a hugely positive development, but that is all the more reason to avoid treating fundraising rhetoric as facts, and to learn lessons from what has happened with such large-scale vertical schemes in the past. As a 2010 editorial in The Lancet observed: 'Evaluation must now become the top priority in global health. Currently, it is only an afterthought ... Without proper monitoring and accountability, countries and donors and taxpayers - have no idea whether or how their investments are working,' (The Lancet 2010, p. 526.) With respect to MDA, there is a need for sober and rigorous assessment, 
which examines locally specific effects and subjects reported results to appropriate critical scrutiny. Even if claims about 'making poverty history' and 'alleviating the suffering of the bottom billion' are set aside as overblown, it is certainly possible that programmes have potential to assist some poor and marginal populations. However, without heeding warnings and amending strategies, that window of opportunity may be lost.

\section{Acknowledgments}

This paper is based on research undertaken as part of a larger programme of work funded by the Bill and Melinda Gates Foundation, assessing the roll out of mass treatment for neglected tropical diseases in sub-Saharan Africa. It was undertaken in collaboration with colleagues from the Schistosomiasis Control Initiative, Imperial College. The authors are enormously grateful to Alan Fenwick, Director of the Programme, for supporting this research. Other colleagues at SCI have also been helpful, most notably Lynsey Blair and Alice Norton. In Tanzania the authors have benefited from challenging discussions with a wide range of personnel working in the health sector, from staff at the National Institute of Medical Research in Mwanza, Muheza and Tanga, to regional and district health staff at all of the research sites. John Changalucha, Roly Gosling, Julie Hastings, the late Nicholas Lwambo, Mwele Malecela, Caroline Maxwell, Ursuline Nyandindi, Caroline Parker and Polly Wingate-Saul have been especially helpful. Fantastic assistance was provided in the field by the late Kombo Iddi, Shumu, Jane, Juma, Mishy, Angela, Nasir and Suleiman. We have benefited too from the detailed and well-informed comments we have received from anonymous reviewers. A final word of thanks is reserved for our children, Josh and Rachael, who proved wonderful accomplices in the field. Research in Tanzania was carried out under the auspices of the National Institute for Medical Research and the Tanzanian Commission for Science and Technology $(\mathrm{COSTECH})$.

\section{References}

Allen, T. \& Parker, M. (2011) The 'Other Diseases' of the Millennium Development Goals: rhetoric and reality of free drug distribution to cure the poor's parasites. Third World Quarterly 32(1), $89-115$.

Allen, T. \& Parker, M. (2012) Will increased funding for neglected tropical diseases really make poverty history? The Lancet 30th January. doi: 10.1016/S0140-6736(08)61345-8.

Allotey, P., Reidpath, D. \& Pokhrel, S. (2010) Social science research in neglected tropical diseases 1: the on-going neglect in neglected tropical diseases. Health Research Policy and Systems 8, 32.

Bockarie, M. J. \& Deb, R. M. (2010) Elimination of lymphatic filariasis: do we have the drugs to complete the job? Current Opinion in Infectious Diseases 23, 617-620.

Butt, L. (2005) "Lipstick girls" and "fallen women": AIDS and conspiratorial thinking in Papua, Indonesia. Cultural Anthropology 20(3), 412-442.

Daily News Online Edition (2008) Rowdy mobs halt bilharzia vaccinations in Morogoro. Daily News, August 30th. URL: http://www.dailynews.co.tz/feature/?search=Rowdy+mob+Morogoro\& searchtext=Search. 
Feldman-Savelsberg, P., Ndonko, F. \& Schmidt-Ehry, B. (2000) Sterilizing vaccines or the politics of the womb: retrospective study of a rumor in Cameroon. Medical Anthropology Quarterly 14(2), 159-179.

Gambhir, M., Bockarie, M., Tisch, D., Kazura, J., Remais, J., Spear, R. \& Michael, E. (2010) Geographic and ecologic heterogeneity in elimination thresholds for the major vector-borne helminthic disease, lymphatic filariasis. BMC Biology $8,22$.

Geissler, P. W. \& Pool, R. (2006) Editorial: Popular concerns about medical research projects in sub-Saharan Africa - a critical voice in debates about medical research ethics. Tropical Medicine and International Health 11(7), 975-982.

Giles, L. (1987) Possession cults on the Swahili coast: a re-examination of theories of marginality. Africa 57(2), 234-258.

Giles, L. (1999) Spirit possession and the symbolic construction of Swahili society. In Behrend, H. \& Luig, U. (eds) Spirit Possession, Modernity, and Power. James Curry, London, pp. 142 164.

Hausmann Muela, S., Muela Ribera, J., Mushi, A. K. \& Tanner, M. (2002) Medical syncretism with reference to malaria in a Tanzanian community. Social Science \& Medicine 55, 403-413.

Hausmann Muela, S., Muela Ribera, J. \& Tanner, M. (1998) Fake malaria and hidden parasites the ambiguity of malaria. Anthropology \& Medicine 5(1), 43-61.

Heald, S. (2002) It's never as easy as ABC: understandings of AIDS in Botswana. African Journal of AIDS Research 1, 1-11.

Hotez, P. J., Fenwick, A., Saviolli, L. \& Molyneux, D. H. (2009) Rescuing the bottom billion through the control of neglected tropical diseases. The Lancet 373, 1570-1575.

IRIN Humanitarian News and Analysis (2008) Tanzania: vaccination campaign treats millions of children. IRIN, 2nd September 2008. URL: http://www.irinnews.org/printreport.aspx? reportid=80123 (accessed 4th April 2012).

Kolstrup, N., McMahon, J. E., Magayuka, S. A., Mosha, F. W., Bushrod, F. M. \& Bryan, J. H. (1981) Control measures against bancroftian filariasis in coastal villages in Tanzania. Annals of Tropical Medicine and Parasitology 75, 433-451.

McCarthy, J. (2005) Is antihelmintic resistance a threat to the program to eliminate lymphatic filariasis? American Journal of Tropical Medicine and Hygiene 73(2), 232-233.

Malecela, M. N., Kilima, P. \& Mackenzie, C. D. (2008) Implementation and management of lymphatic filariasis control and elimination programmes: the Tanzanian experience. In Simonsen, P. E., Malecela, M. N., Michael, E. \& Mackenzie, C. D. (eds) Lymphatic Filariasis: Research and Control in Eastern and Southern Africa. DBL - Centre for Research and Development, pp. 111123.

Malecela, M. N., Lazarus, W., Mwingira, U., Mwakitalu, E., Makene, C., Kabali, C. \& Mackenzie, C. (2009a) Eliminating LF: a progress report from Tanzania. Journal of Lymphoedema 4, 10-12.

Malecela, M. N, Mwingira, U., Mwakitalu, M. E., Kabali, C., Michael, E. \& Mackenzie, C. D. (2009b) The sharp end - experiences from the Tanzanian programme for the elimination of lymphatic filariasis: notes from the end of the road. Annals of Tropical Medicine and Parasitology 103 (Supplement 1), S53-S57.

Meyrowitsch, D. W., Simonsen, P. E. \& Magesa, S. M. (2004) A 26-year follow-up of bancroftian filariasis in two communities in north-eastern Tanzania. Annals of Tropical Medicine and Parasitology 98, 155-169.

Meyrowitsch, D. W., Simonsen, P. E. \& Makunde, W. H. (1995) Bancroftian filariasis: analysis of infection and disease in five endemic communities of north-eastern Tanzania. Annals of Tropical Medicine and Parasitology 89, 653-663.

Michael, E., Malecela, M. N., Zervos, M. \& Kazura, J. W. (2008) Global eradication of lymphatic filariasis: the value of chronic disease control in parasite elimination. PLoS ONE 3(8), e2936. 
Michael, E., Malecela-Lazaro, M., Simonsen, P. E., Pedersen, E. M., Barker, G., Kumar, A. \& Kazura, J. W. (2004) Mathematical modelling and the control of lymphatic filariasis. The Lancet Infectious Diseases 4, 223-234.

Mohammed, K. A. (2008) The current status of lymphatic filariasis and its control in Zanzibar. In Simonsen, P. E., Malecela, M. N., Michael, E. \& Mackenzie, D. D. Lymphatic Filariasis: Research and Control in Eastern and Southern Africa. DBL - Centre for Research and Development, Abstract No. 7, pp. 160-161.

Mohammed, K. A., Molyneux, D. H., Albonico, M. \& Rio, F. (2006) Progress towards eliminating lymphatic filariasis in Zanzibar: a model programme. TRENDS in Parasitology 22(7), 340-344.

Molyneux, D. (2003) Lymphatic filariasis (elephantiasis) elimination: a public health success and development opportunity. Filaria Journal 2, 13.

Molyneux, D. H., Hotez, P. J. \& Fenwick, A. (2005) 'Rapid impact interventions': how a policy of integrated control for Africa's neglected tropical diseases could benefit the poor. PLoS Med 2(11), e336.

Niehaus, I. \& Jonsson, G. (2005) Dr. Wouter Basson, Americans, and wild beasts: men's conspiracy theories of HIV/AIDS in the South African Lowveld. Medical Anthropology: CrossCultural Studies in Health and Illness 24(2), 179-208.

Nielsen, N. O., Simonsen, P. E., Magnussen, P., Magesa, S. \& Friis, H. (2006) Cross-sectional relationship between HIV, lymphatic filariasis and other parasitic diseases in coastal, northeastern Tanzania. Transactions of the Royal Society of Tropical Medicine and Hygiene 100, $543-550$.

Ottesen, E. A., Hooper, P. J., Bradley, M. \& Biswas, G. (2008) The global programme to eliminate lymphatic filariasis: health impact after 8 years. PLoS Neglected Tropical Diseases 2(10), e317.

Parker, M. \& Allen, T. (2011) Does mass drug administration for the integrated treatment of neglected tropical diseases really work? Assessing evidence for the control of schistosomiasis and soil-transmitted helminths in Uganda. Health Research Policy and Systems 9, 3.

Parker, M., Allen, T. \& Hastings, J. (2008) Resisting control of neglected tropical diseases: dilemmas in the mass treatment of schistosomiasis and soil-transmitted helminths in north-west Uganda. Journal of Biosocial Science 40, 161-181.

Parker, M., Allen, T., Pearson, G., Peach, N., Flynn, R. \& Rees, N. (2012) Border parasites: schistosomiasis control among Uganda's fisherfolk. Journal of East African Studies 6(1), 97-122.

Renne, E. P. (2010) The Politics of Polio in Northern Nigeria. Indiana University Press.

Rwegoshora, R. T., Simonsen, P. E., Meyrowitsch, D. W., Malecela-Lazaro, M. N., Michael, E. \& Pedersen, E. M. (2007) Bancroftian filariasis: house-to-house variation in the vectors and transmission - and the relationship to human infection - in an endemic community of coastal Tanzania. Annals of Tropical Medicine and Parasitology 101(1), 51-60.

Simonsen, P. E., Meyrowitsch, D. W., Makunde, W. H. \& Magnussen, P. (1995) Bancroftian filariasis: the pattern of microfilaraemia and clinical manifestations in three endemic communities in northeastern Tanzania. Acta Tropica 60, 179-187.

Simonsen, P. E., Pederson, E. M., Rwegoshora, R. T., Malecela, M. N., Derua, Y. A. \& Magesa, S. (2010) Lymphatic filariasis control in Tanzania: effect of repeated mass drug administration with ivermectin and albendazole on infection and transmission. PLoS Neglected Tropical Diseases 4(6), e696.

Taylor, M. J., Hoeruf, A. \& Bockarie, M. (2010) Lymphatic filariasis and onchocerciasis. The Lancet 377, 1175-1185.

The Lancet (2010) Evaluation: the top priority for global health. The Lancet 375(9714), 526.

United Republic of Tanzania (2009) Neglected Tropical Diseases Country Plan, 2009-2014. Ministry of Health and Social Welfare, Dar es Salaam. URL: http://www.ntd.rti.org/publications/ index.cfm?fuseaction=throwpub\&id=294 (accessed 27th March 2012). 
White, L. (2000) Speaking With Vampires: Rumor and History in Colonial Africa. University of California Press, Berkeley.

Wingate-Saul, P. (2008) The Distribution of Praziquantel to School Children and Adults in Ukerewe District, Tanzania. Report submitted to Schistosomiasis Control Initiative, Imperial College, London.

World Health Organization (2012) Lymphatic Filariasis Programme. URL: http://www.who.int/ lymphatic_filariasis/disease/en/ (accessed 27th March 2012).

Yahya, M. (2007) Polio vaccines - "No thank you!" Barriers to polio eradication in northern Nigeria. African Affairs 106, 185-204. 